\title{
Epidemiological and Clinical Characteristics of COVID-19 Patients Studied by Jiroft University of Medical Sciences: Southeast of Iran

\author{
Esmat Rezabeigi-Davarani $^{1(D)}$, Saied Bokaie ${ }^{2}$, Vahid Mashayekhi ${ }^{3}$ (D) Laleh Sharifi ${ }^{4}$, \\ Reza Faryabis (D), Shohreh Alian Samakkhah6 (D), Ahad Ashrafi Asgarabad ${ }^{7}$ (D), \\ Kiavash Hushmandi ${ }^{2}$, Mehdi Raei ${ }^{8}$ (D), Salman Daneshi ${ }^{*}$ (iD)
}

1. Health in Disasters and Emergencies Research Center, Institute for Futures Studies in Health, Kerman University of Medical Sciences, Kerman, Iran

2. Dept. of Food Hygiene and Quality Control, Division of Epidemiology \& Zoonoses, Faculty of Veterinary Medicine, University of Tehran, Tehran, Iran

3. Deputy of Health, Jiroft University of Medical University, Jiroft, Iran

4. Uro-Oncology Research Center, Tehran University of Medical Sciences, Tehran, Iran

5. Dept of Public Health, School of Public Health, Jiroft University of Medical Sciences, Jiroft, Iran

6. Dept. of Food Hygiene, Faculty of Veterinary Medicine, University of Special Modern Technologies, Amol, Iran

7. Dept. of Public Health, School of Health, Bam University of Medical Sciences, Bam, Iran

8. Health Research Center, Life Style Institute, Baqiyatallah University of Medical Sciences, Tehran, Iran

\begin{tabular}{|c|c|}
\hline Article Info & ABSTRACT \\
\hline dol $10.30699 /$ jambs.29.136.303 & Background \& Objective: The behavior of COVID-19, clinical symptoms, and \\
\hline $\begin{array}{l}\text { Received: 2020/10/05; } \\
\text { Accepted: 2021/01/13; }\end{array}$ & $\begin{array}{l}\text { mortality rate are not the same in different regions. Due to lack of knowledge about } \\
\text { the cited issues, we aimed to investigate the clinical symptoms, case fatality rate, } \\
\text { and some risk factors of COVID-19. }\end{array}$ \\
\hline Published Online: 04 Apr 2021; & Materials \& Methods: This longitudinal study was started from the late February \\
\hline $\begin{array}{l}\text { Use your device to scan and read the } \\
\text { article online }\end{array}$ & $\begin{array}{l}2020 \text { and lasted to the mid-July } 2020 \text { in Jiroft, Kerman province, Iran. The course of } \\
\text { the disease, clinical signs and symptoms, underlying diseases, patients' exposure } \\
\text { history, travel history, adherence to health instructions, and the fatality rate of the } \\
\text { disease were evaluated in the patients. The descriptive statistics and frequency were } \\
\text { analyzed in different groups using IBM SPSS statistics version } 20 \text {. }\end{array}$ \\
\hline 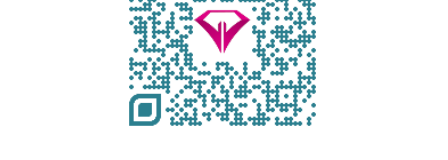 & $\begin{array}{l}\text { Results: In this study, } 2977 \text { definitive cases of COVID-19 were detected using RT- } \\
\text { PCR test. The frequent clinical symptoms were fever }(45.2 \%) \text {, body aches and bruises } \\
(38.8 \%) \text {, and cough }(36.4 \%) \text {, respectively. The fatality rate of the disease was } 4 \% \text {. } \\
\text { Evaluation of the patients' exposure history showed that almost } 50 \% \text { of the cases had }\end{array}$ \\
\hline \multirow{4}{*}{$\begin{array}{l}\text { Corresponding Information: } \\
\text { Salman Daneshi } \\
\text { Department of Public Health, School of } \\
\text { Health, Jiroft University of Medical } \\
\text { Sciences, Jiroft, Iran } \\
\text { E-Mail: } \\
\text { salmandaneshi008@gmail.com }\end{array}$} & $\begin{array}{l}\text { no exposure. Among the studied individuals, } 33 \% \text { had the nistory of exposure to a } \\
\text { definite COVID-19 case. }\end{array}$ \\
\hline & Conclusion: Personal hygiene, social distancing, and use of face mask are of great \\
\hline & $\begin{array}{l}\text { importance in reducing the disease morbidity and mortality. Public awareness about } \\
\text { COVID-19 should also be increased, especially in the elderly individuals with the } \\
\text { history of underlying and chronic diseases. }\end{array}$ \\
\hline & Keywords: Coronavirus, COVID-19, Epidemiology, Mortality, Patient \\
\hline 2021, This is & $\begin{array}{l}\text { cle distributed under the terms of the Creative Com } \\
\text { mercial usages with proper citation. }\end{array}$ \\
\hline
\end{tabular}

\section{Introduction}

COVID-19 disease began in December 2019 in Wuhan, China (1). In a short time, the virus spread within China and between other countries (2). The virus has increased world concern because of its high transmission rate, as well as high mobility and mortality among humans (3). The World Health Organization (WHO) declared COVID-19 disease as a pandemic in March 2020 (4). In Islamic Republic of Iran, the first cases were reported in Qom on February 19, 2020; then it spread to other regions of the country, quickly (5). Today, the COVID-19 pandemic is one of the most important public health issues in the country (6).

COVID-19 disease is caused by a new virus belonging to the family of Coronaviridae (genus of beta coronavirus) (7-9). Coronaviruses are a large family of viruses that can cause systemic infections in various animals, mainly respiratory infections such as acute respiratory syndrome (SARS) and Middle East respiratory syndrome (MERS) in humans $(10,11)$. The other end of coronavirus species spectrum is the common cold virus with relatively mild symptoms $(12,13)$. 
COVID-19 disease is highly contagious and each infected person could infect at least three other people on average (14). Qifang et al. (2020) found that having an infected family member and traveling with an infected person increase the chance of morbidity (15).

The clinical signs of the disease begin after a period of almost 2.5 days, whereas the incubation period can extend to 14 days. Its duration depends on various factors, including the age and the immune system of the patient (16). The disease is classified into mild, moderate, severe, and critical $(17,18)$. The majority of COVID-19 cases are mild $(17,19)$. The most common symptoms are fever, fatigue, dry cough, and diarrhea $(17,20)$.

Some patients only indicate neurological symptoms as the initial symptoms, such as headache, languidness, unstable walking, malaise, cerebral hemorrhage, and cerebral infarction (20). Clinical studies have shown that the incidence of diarrhea ranges from $2-50 \%$ in patients (21).

Complications such as severe pneumonia, respiratory failure, acute respiratory distress syndrome (ARDS), heart damage and lymphopenia, sepsis and septic shock have been reported as fatal consequences (19, 22-24).

The disease has a mortality rate of approximately $7.5 \%$. Elderly patients or those with chronic, cardiovascular and respiratory diseases are at higher risk of death (25). However, mortality rate varies from one country to another $(14,26-28)$. Considering the emergence of the disease and the lack of comprehensive knowledge about the behavior of the virus, our understanding of the clinical spectrum of COVID-19 infection is not yet complete. Moreover, different clinical symptoms and mortality rates have been reported in different regions $(14,17,26,29)$; therefore, we decided to identify clinical signs, case fatality rate, and some risk factors in COVID-19 patients diagnosed with RT-PCR.

\section{Materials and Methods}

This study was a longitudinal study conducted on the population of the southern regions of Kerman province (about 700,000 people), who were monitored for 5 months from the late February 2020 to the mid-July 2020. As soon as the occurrence of new cases of COVID-19, all definitive cases were included in the study based on the diagnosis by RT-PCR.

The data were collected by a checklist prepared by the researchers, including demographic information, disease progression, patients' clinical signs, improved cases and deaths, underlying diseases, and patients' exposure history, comprising exposure to suspicious, probable, and definite cases. Moreover, the relation of new cases with definite cases, their travel history during 1-14 days before the appearance of the first signs of disease, and adherence to health instructions, as well as the disease lethality were assessed.

The collected data were entered into the software; they were analyzed using descriptive statistics and frequency in different groups using IBM SPSS statistics version 20.0 (IBM Corp. Released 2011. IBM SPSS Statistics for Windows, Version 20.0. Armonk, NY: IBM Corp.). The following formula was used to calculate the lethality of COVID-19 disease (30). The case fatality rate was calculated as follows:

Case fatality (\%): (No. of deaths due to disease during a specific period of time after disease onset or diagnosis) / (No. of confirmed cases with the specified disease) $\times 100$

The Ethics Committee of Jiroft University of Medical Sciences, Kerman, Iran, approved this study (IR.JMU.REC.1399.001).

\section{Results}

A number of 2977 positive cases were detected during the study, from which 1828 (61.4\%) were outpatients and 1149 (38.6\%) were hospitalized. The demographic variables are indicated in Table 1.

Table 1. Demographic variables of patients with COVID-19 in southern Iran

\begin{tabular}{|ccc|}
\hline Gender & Absolute Frequency & Relative Frequency $(\%)$ \\
\hline Male & 1510 & 50.7 \\
\hline Female & 1467 & 49.3 \\
Sum & 2977 & 100 \\
\hline Age Group & & \\
$\mathbf{< 5}$ & 12 & 0.4 \\
$\mathbf{6 - 1 7}$ & 48 & 1.6 \\
$\mathbf{1 8 - 2 9}$ & 583 & 19.6 \\
\hline $\mathbf{3 0 - 5 9}$ & 1721 & 57.8 \\
\hline
\end{tabular}




\begin{tabular}{|c|c|c|}
\hline Gender & Absolute Frequency & Relative Frequency (\%) \\
\hline$>60$ & 613 & 20.6 \\
\hline Sum & 2977 & 100 \\
\hline \multicolumn{3}{|l|}{ Education } \\
\hline Child & 18 & 0.6 \\
\hline Illiterate & 669 & 22.5 \\
\hline primary & 323 & 10.8 \\
\hline Middle School & 194 & 6.5 \\
\hline High School & 70 & 2.4 \\
\hline Diploma & 566 & 19 \\
\hline Associate Degree & 194 & 6.5 \\
\hline Bachelor & 726 & 24.4 \\
\hline M.s & 180 & 6 \\
\hline Doctorate & 37 & 1.2 \\
\hline Sum & 2977 & 100 \\
\hline \multicolumn{3}{|l|}{ Area of residence } \\
\hline Urban & 1830 & 61.5 \\
\hline rural & 1147 & 38.5 \\
\hline Sum & 2977 & 100 \\
\hline \multicolumn{3}{|l|}{ Job } \\
\hline Employee & 1001 & 33.6 \\
\hline housewife & 906 & 30.4 \\
\hline Farmer / rancher & 282 & 9.5 \\
\hline Student & 87 & 2.9 \\
\hline Driver & 45 & 1.5 \\
\hline Seller & 84 & 2.8 \\
\hline manual worker & 92 & 3.1 \\
\hline Child & 18 & 0.6 \\
\hline Unemployed / Retired & 271 & 9.1 \\
\hline Freelance & 191 & 6.4 \\
\hline Sum & 2977 & 100 \\
\hline
\end{tabular}

Among the studied population, the case fatality rate was equal to $4 \%$. The most frequent clinical symptoms were fever $(45.2 \%)$, body pain and contusion $(38.8 \%)$, cough $(36.4 \%)$, and headache $(27.3 \%)$, respectively. The least found symptoms were confusion and irritability $(3.9 \%)$, constipation $(0.2 \%)$, and skin symptoms $(0.0004 \%)$; other symptoms have been shown in Figure 1.

Among the fatalities, $27 \%$ had cardiovascular disease, followed by $16 \%$ with diabetes and respiratory diseases. Cancer, addiction, kidney and liver disorders, neurological and blood diseases, and immune deficiencies are also important in this regard (Figure 2).
In view of exposure history, approximately $50 \%$ of the cases had no exposure history and the rest had a history of exposure to definite cases $(33 \%)$, probable cases $(15 \%)$, and suspected cases $(2 \%)$. The highest proportion of exposure was between family members, followed by friends, colleagues, and neighbors. Among all definite cases, $22 \%$ had no history of traveling and $78 \%$ had no history of traveling within the country; only $1 \%$ of cases had the history of traveling abroad.

Considering the personal hygiene and social distancing among definite cases, 29\%, 63\%, and 8\% were poor, good, and excellent, respectively. Thirteen percent of infected individuals were employed by 
health care providers, and $31 \%$ had a history of referral to health care facilities within 14 days prior to the onset of symptoms. Among the total number of cases, 399 $(16 \%)$ were health care personnel; the highest number of cases were related to hospitals (54\%), health centers $(22 \%)$, public and private laboratories $(9.1 \%)$, and public and private clinics $(7.3 \%)$, respectively. The rest of patients were staffs of the university headquarters.

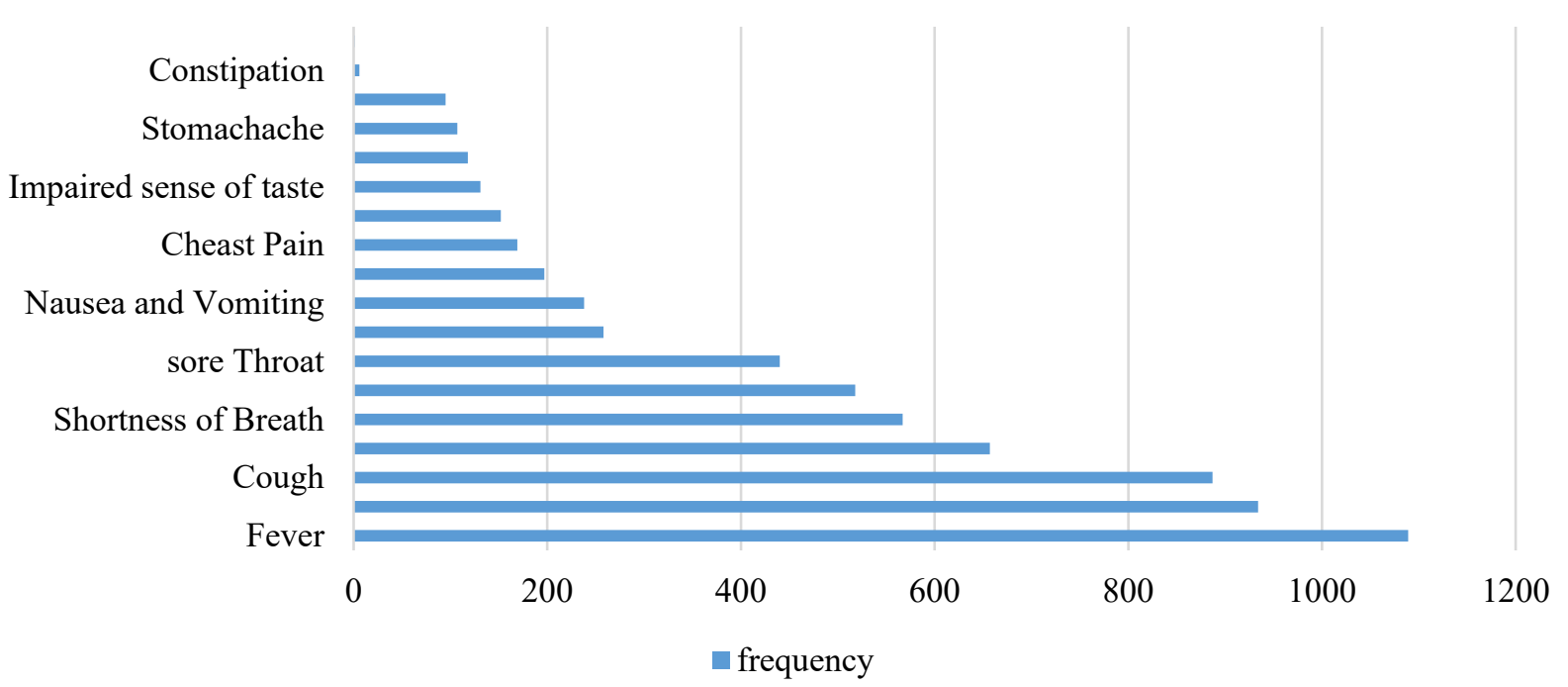

Figure 1. Frequency distribution of clinical symptoms caused by COVID-19, in the studied population

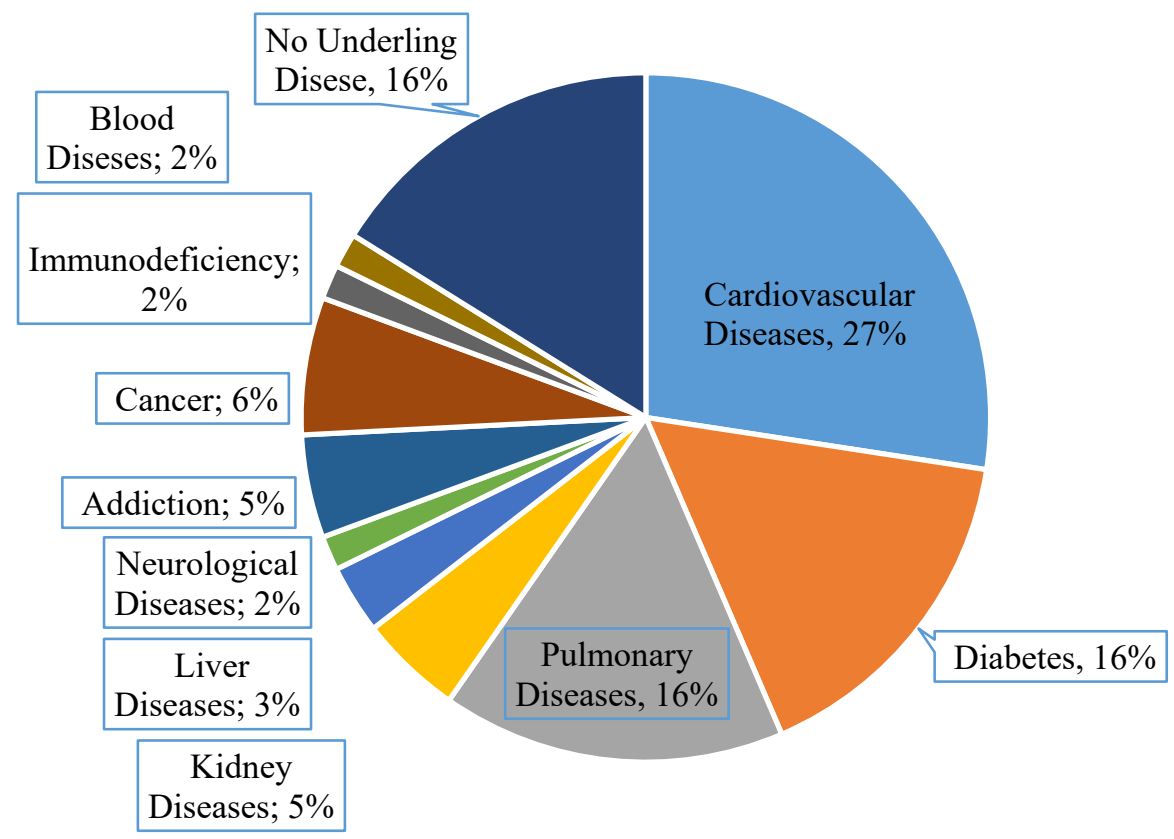

Figure 2. Frequency of underlying diseases among occurred deaths due to COVID-19.

\section{Discussion}

The present study evaluated the epidemiological characteristics, clinical signs, mortality rate, and some related risk factors of COVID-19 disease in Jiroft, Kerman province, Iran. According to the results of the present study, $50.7 \%$ of the cases were male and about $57.8 \%$ of them were in the age range of $30-59$ years.
The study of Akbari et al. (2020) conducted in Shiraz city (southern Iran) showed that $56.6 \%$ of patients were male and $38.4 \%$ were in the age range of 40-60 years (4). In the study of Araban et al. (2020), which was conducted in Saveh city (Iran), the most cases were male and over 65 years (16). In 2020, Guan 
et al. examined the demographic characteristics and clinical signs of patients with coronavirus infection in China; $58 \%$ of the patients were male and the mean age of the patients was 47 years (23). In another study in China, $54 \%$ of cases were male and $82 \%$ were under 60 (31). Based on the results, most affected people were men and women were less affected; this could be due to female sex hormones and the presence of the $\mathrm{X}$ chromosome which can be effective in this regard. Another reason could be higher rate of smoking among men (32).

Regarding the relationship between the age and cases of COVID-19, it can be asserted that older people are more likely to have underlying diseases and weaker immune system. In the study population, the case fatality rate of the disease was $4 \%$, which was almost similar to the results of the study of Akbari et al. (2020) in Shiraz (3\%) (4). The case fatality rate was $10.8 \%$ in Saveh (Iran) (16), which was more than the present study. In the study of Nikpouraghdam et al. in Tehran, the case fatality rate was $8 \%$ and $1.85 \%$ among hospitalized and non-hospitalized patients, respectively (14). The mortality rate of the disease varies in different provinces of Iran and also in different countries; it is $4.3 \%$ in China, $5-17 \%$ in Italy, and about $1 \%$ in South Korea and Germany $(28,31)$. Difference in mortality rate may be due to the racial differences and genetic backgrounds, socio-cultural behaviors, different health care, more experienced treatment staff, and more advanced hospital equipment.

According to the results of the present study, the most common clinical symptoms were fever $(45.2 \%)$, body aches and bruises (38.8\%), cough (36.4\%), and headache $(27.3 \%)$. Our findings were parallel to the results from another study in Iran, which reported cough in $44.5 \%$, fever in $41.8 \%$, and shortness of breath (dyspnea) in $40.1 \%$ of patients (16). However, in a study by Zhao et al. in China, a higher percentage of patients showed following symptoms: fever $(82.4 \%)$, cough $(64.8 \%)$, and fatigue (38.5\%) (31). Therefore, fever, cough, dyspnea, and fatigue are common symptoms of the disease $(33,34)$; however, there are other symptoms such as gastrointestinal symptoms, heart attack, stroke, and kidney damage seen in some COVID-19 infected cases (35). In the present study, cardiovascular problems, diabetes, and respiratory diseases were seen among the fatalities.

In the study by Araban et al. (2020), half of all deaths occurred in people with underlying diseases. Hypertension, diabetes, and cardiovascular diseases were considered as important risk factors for COVID19; they were significantly associated with mortality (16). One study found that diabetes, respiratory disease, hypertension, and cardiovascular disease increase the risk of death in people with COVID-19 (14). Based on the results of the present study, in reviewing the exposure history of patients with COVID-19, 33\% had close contact with a definite case of disease. The highest proportion was between family members, followed by friends, colleagues, and neighbors.

Among all cases, $22 \%$ had the history of travel. Twenty-nine percent of definite cases had poor personal hygiene and social distancing. Thirty-one percent of cases had the history of referring to health centers during the 14 days before the onset of symptoms. Therefore, preventive strategies such as using a mask, washing hands regularly with water and soap or using alcohol-containing solutions, and educating people should be considered (36). Social distancing (at least 6 feet), avoiding close contact with people, and avoiding gatherings can be effective in controlling the disease (37).

\section{Conclusion}

Patients with COVID-19 experience a wide range of clinical symptoms, and not a definite or specific symptom has been recognized for the disease. People with underlying, chronic, cardiovascular and respiratory diseases, and the elderly people are highrisk individuals. Considering different routes of transmission (direct contact with an infected person and respiratory transmission), the best way to deal with the disease is to follow personal hygiene practices and observe social distancing rules, as well as using mask. Moreover, it is important to educate and raise public awareness about this disease in order to reduce its morbidity and mortality especially in the elderly people with a history of underlying and chronic diseases.

\section{Acknowledgments}

None.

\section{Conflict of Interest}

The authors declared that they have no conflicts of interest.

\section{References}

1. Chen N, Zhou M, Dong X, et al. Epidemiological and clinical characteristics of 99 cases of 2019 novel coronavirus pneumonia in Wuhan, China: a descriptive study. The Lancet. 2020;395(10223):507-13. [DOI: 10.1016/S0140-6736(20)30211-7]

2. Giovanetti M, Benvenuto D, Angeletti S, Ciccozzi M. The first two cases of 2019-nCoV in Italy: Where they come from? J Med Virol. 2020;92(5):518-21. [DOI:10.1002/jmv.25699]

3. Zhao D, Yao F, Wang L, et al. A comparative study on the clinical features of COVID-19 
pneumonia to other pneumonias. Clin Infect Dis. 2020. ciaa247. [DOI:10.1093/cid/ciaa247]

4. Akbari A, Emami A, Javanmardi F, Pirbonyeh N, Fadakar N. Early epidemiological analysis of COVID-19: first report from South of Iran. 2020. [DOI: 10.21203/rs.3.rs-19915/v1]

5. Shahnazi H, Ahmadi-Livani M, Pahlavanzadeh B, Rajabi A, Hamrah MS, Charkazi A. Assessing preventive health behaviors from COVID-19: a cross sectional study with health belief model in Golestan Province, Northern of Iran. Infect Dis Poverty. 2020;9(1):1-9. [DOI:10.1186/s40249020-00776-2]

6. Devi S. COVID-19 resurgence in Iran. Lancet (London, England). 2020;395(10241):1896. [DOI: 10.1016/S0140-6736(20)31407-0]

7. Lai CC, Shih TP, Ko WC, Tang HJ, Hsueh PR. Severe acute respiratory syndrome coronavirus 2 (SARS-CoV-2) and corona virus disease-2019 (COVID-19): the epidemic and the challenges. Int J Antimicrob Agents. 2020:105924. [DOI:10.1016/j.ijantimicag.2020.105924]

8. Li X, Zai J, Zhao Q, et al. Evolutionary history, potential intermediate animal host, and crossspecies analyses of SARS-CoV-2. J Med Virol. 2020;92(6):602-11. [DOI:10.1002/jmv.25731]

9. Lu R, Zhao X, Li J, et al. Genomic characterisation and epidemiology of 2019 novel coronavirus: implications for virus origins and receptor binding. The Lancet. 2020;395(10224):565-74.

[DOI: 10.1016/S0140-6736(20)30251-8]

10. Yin Y, Wunderink RG. MERS, SARS and other coronaviruses as causes of pneumonia. Respirol. 2018;23(2):130-7. [DOI:10.1111/resp.13196]

11. Zaki AM, Van Boheemen S, Bestebroer TM, Osterhaus AD, Fouchier RA. Isolation of a novel coronavirus from a man with pneumonia in Saudi Arabia. New Eng J Med. 2012;367(19):1814-20. [DOI: 10.1056/NEJMoa1211721]

12. Su S, Wong G, Shi W, et al. Epidemiology, genetic recombination, and pathogenesis of coronaviruses. Trend Microb. 2016;24(6):490502. [DOI:10.1016/j.tim.2016.03.003]

13. Lu H, Stratton CW, Tang YW. Outbreak of pneumonia of unknown etiology in Wuhan, China: The mystery and the miracle. J Med Virol. 2020;92(4):401-2. [DOI:10.1002/jmv.25678]

14. Nikpouraghdam M, Farahani AJ, Alishiri G, et al. Epidemiological characteristics of coronavirus disease 2019 (COVID-19) patients in IRAN: A single center study. J Clin Virol. 2020. 127: 104378 [DOI: 10.1016/j.jcv.2020.104378]
15. Bi Q, Wu Y, Mei S, et al. Epidemiology and transmission of COVID-19 in 391 cases and 1286 of their close contacts in Shenzhen, China: a retrospective cohort study. The Lancet Infectious Diseases. 2020. [DOI:10.1016/S14733099(20)30287-5]

16. Araban M, Karimy M, Mesri M, Armoon B, Koohestani HR, Azani H. Epidemiological, clinical characteristics of coronavirus-infected disease (COVID-19) among sample of Iranian community: funding from survey in central of Iran. 2020. [DOI:10.21203/rs.3.rs-32797/v1]

17. Hassan SA, Sheikh FN, Jamal S, Ezeh JK, Akhtar A. Coronavirus (COVID-19): a review of clinical features, diagnosis, and treatment. Cureus. 2020;12(3): [DOI:10.7759/cureus.7355]

e7355

18. Wang Y, Chen Y, Qin Q. Unique epidemiological and clinical features of the emerging 2019 novel coronavirus pneumonia (COVID-19) implicate special control measures. J Med Virol. 2020;92(6):568-76. [DOI:10.1002/jmv.25748]

19. Cascella M, Rajnik M, Cuomo A, Dulebohn SC, Di Napoli R. Features, evaluation and treatment coronavirus (COVID-19). Statpearls [internet]: StatPearls Publishing; 2020.

20. Wang HY, Li XL, Yan ZR, Sun XP, Han J, Zhang BW. Potential neurological symptoms of COVID-19. Therap Adv Neurol Disorder. 2020;13:1756286420917830. [DOI: 10.1177/1756286420917830]

21. D'Amico F, Baumgart DC, Danese S, PeyrinBiroulet L. Diarrhea during COVID-19 infection: pathogenesis, epidemiology, prevention and management. Clin Gastroenterol Hepatol. 2020. 18(8):1663-72

\section{[DOI:10.1016/j.cgh.2020.04.001]}

22. Holshue ML, DeBolt C, Lindquist S, et al. First case of 2019 novel coronavirus in the United States. New Eng J Medicine. 2020. 382(10):92936 [DOI:10.1056/NEJMoa2001191]

23. Guan WJ, Ni ZY, Hu Y, et al. Clinical characteristics of 2019 novel coronavirus infection in China. MedRxiv. 2020.

24. Kanne JP. Chest CT findings in 2019 novel coronavirus (2019-nCoV) infections from Wuhan, China: key points for the radiologist. Radiol Soc North Am. 2020. 295(1):16-17 [DOI:10.1148/radiol.2020200241]

25. Wang Z, Yang B, Li Q, Wen L, Zhang R. Clinical features of 69 cases with coronavirus disease 2019 in Wuhan, China. Clin Infect Dis. 2020. 71(15):769-77 [DOI:10.1093/cid/ciaa272] 
26. Huang C, Wang Y, Li X, et al. Clinical features of patients infected with 2019 novel coronavirus in Wuhan, China. The lancet. 2020;395(10223):497-506. [DOI: 10.1016/S0140-6736(20)30183-5]

27. Wang $\mathrm{D}, \mathrm{Hu} \mathrm{B}, \mathrm{Hu} \mathrm{C}$, et al. Clinical characteristics of 138 hospitalized patients with 2019 novel coronavirus-infected pneumonia in Wuhan, China. JAMA. 2020;323(11):1061-9. [DOI: 10.1001/jama.2020.1585]

28. Giangreco G. Case fatality rate analysis of Italian COVID-19 outbreak. J Med Virol. 2020. ciaa272 [DOI: 10.1002/jmv.25894]

29. Goyal P, Choi JJ, Pinheiro LC, et al. Clinical characteristics of COVID-19 in New York city. $\mathrm{N}$ Eng J Med. 2020. 382(24):2372-74 [DOI:10.1056/NEJMc2010419]

30. Gordis L. The epidemiologic approach to evaluating screening programs. Epidemiology (4th edition) Saunders. 2009;311.

31. Zhao XY, $\mathrm{Xu} \mathrm{XX}$, Yin HS, et al. Clinical characteristics of patients with 2019 coronavirus disease in a non-Wuhan area of Hubei Province, China: a retrospective study. BMC Infect Dis. 2020;20:1-8. [DOI:10.1186/s12879-02005010-w]

32. Cai H. Sex difference and smoking predisposition in patients with COVID-19. Lancet Respir Med. 2020;8(4):e20.

2600(20)30117-X]

[DOI:10.1016/S2213-

33. Adhikari SP, Meng $\mathrm{S}$, $\mathrm{Wu} \mathrm{YJ}$, et al. Epidemiology, causes, clinical manifestation and diagnosis, prevention and control of coronavirus disease (COVID-19) during the early outbreak period: a scoping review. Infect Dis Pover. 2020;9(1):1-12. [DOI:10.1186/s40249-02000646-x]

34. Singhal T. A review of coronavirus disease-2019 (COVID-19). Indian J Pediatr. 2020:1-6. [DOI:10.1007/s12098-020-03263-6]

35. Yao X, Li T, He Z, et al. A pathological report of three COVID-19 cases by minimally invasive autopsies. Chinese J Pathol. 2020;49:E009-E.

36. Chen X, Ran L, Liu Q, Hu Q, Du X, Tan X. Hand hygiene, mask-wearing behaviors and its associated factors during the COVID-19 epidemic: A cross-sectional study among primary school students in Wuhan, China. Int J Environment Res Pub Health. 2020;17(8):2893. [DOI: 10.3390/ijerph17082893]

37. Ha KM. The principle of distance during COVID-19 outbreak in Korea. Int Microbiol. 2020;23(4):641-3. [DOI:10.1007/s10123-02000138-w].

\section{How to Cite This Article:}

Rezabeigi-Davarani E, Bokaie S, Mashayekhi V, Sharifi L, Faryabi R, Alian Samakkhah S, et al Epidemiological and Clinical Characteristics of COVID-19 Patients Studied by Jiroft University of Medical Sciences: Southeast of Iran. J Adv Med Biomed Res. 2021; 29 (136) :302-308

Download citation:

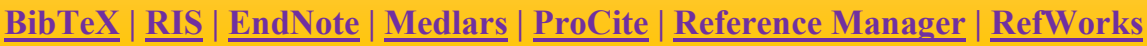

\section{Send citation to:}

(83. Mendeley 2 Zotero i) RefWorks RefWorks 